This item was submitted to Loughborough's Research Repository by the author.

Items in Figshare are protected by copyright, with all rights reserved, unless otherwise indicated.

\title{
Constrained sintering kinetics of 3YSZ films
}

PLEASE CITE THE PUBLISHED VERSION

http://dx.doi.org/10.1016/j.jeurceramsoc.2011.05.044

\section{PUBLISHER}

(c) Elsevier Ltd.

\section{VERSION}

AM (Accepted Manuscript)

\section{LICENCE}

CC BY-NC-ND 4.0

\section{REPOSITORY RECORD}

Kim, Jung-Sik, Robert A. Rudkin, Xin Wang, and Alan Atkinson. 2012. "Constrained Sintering Kinetics of 3 YSZ Films". figshare. https://hdl.handle.net/2134/11176. 
This item was submitted to Loughborough's Institutional Repository (https://dspace.lboro.ac.uk/) by the author and is made available under the following Creative Commons Licence conditions.

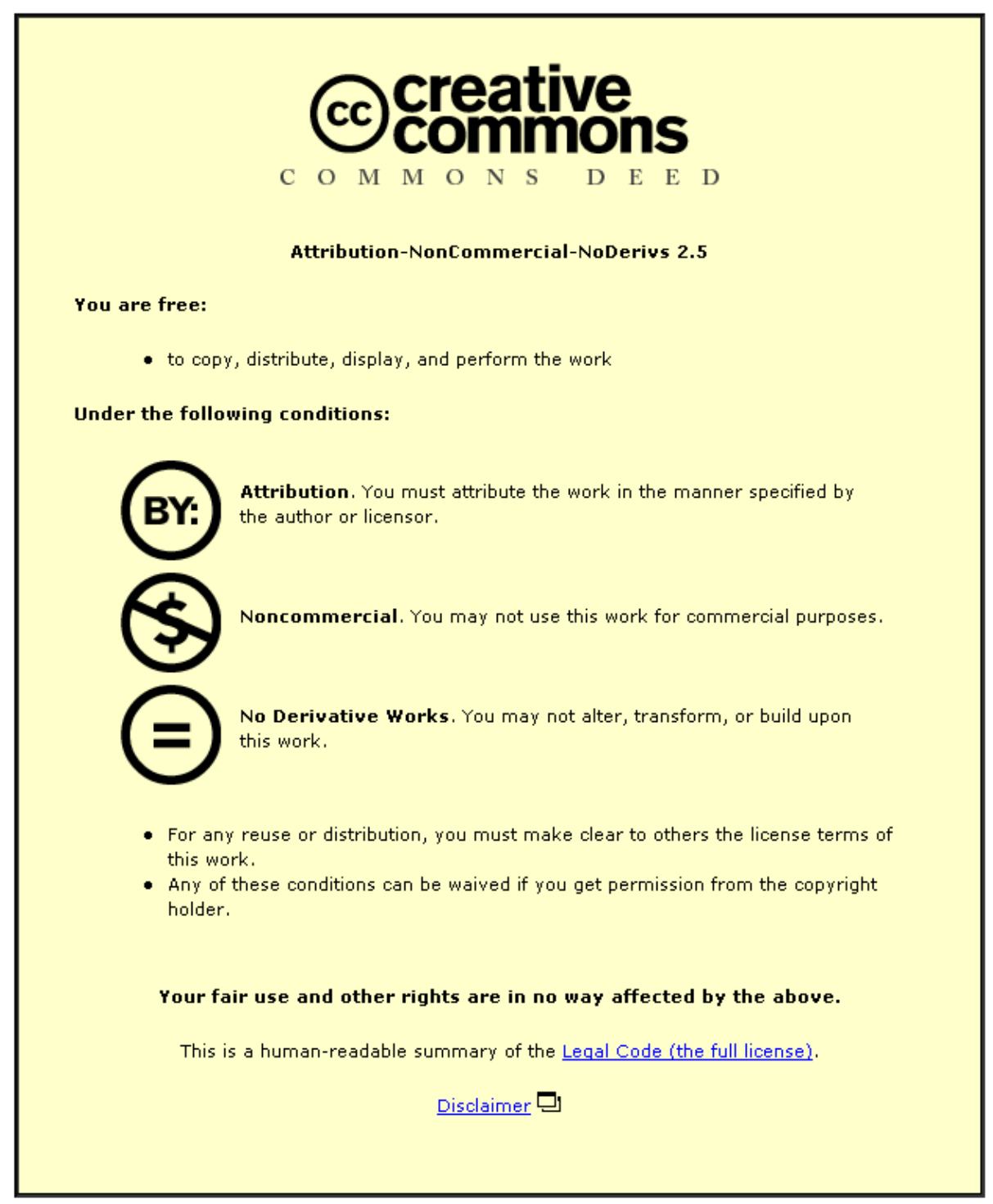

For the full text of this licence, please go to: http://creativecommons.org/licenses/by-nc-nd/2.5/ 


\title{
Constrained sintering kinetics of 3YSZ films
}

Jung-Sik Kim, Robert A. Rudkin, Xin Wang and Alan Atkinson

Department of Materials, Imperial College, London SW7 2AZ, UK.

\begin{abstract}
An optical dilatometer has been constructed to measure the sintering of films constrained by a substrate. The dilatometer is able to resolve changes in film thickness of approximately $50 \mathrm{~nm}$ under typical isothermal sintering conditions at up to $1400^{\circ} \mathrm{C}$. It has been applied to study the densification kinetics of $3 \mathrm{YSZ}$ green layers approximately $10 \mu \mathrm{m}$ thick screenprinted onto $3 \mathrm{YSZ}$ substrates and sintered at temperatures in the range 1100 to $1350^{\circ} \mathrm{C}$. The free densification rates of the same powder in the form of pellets and free-standing films were also measured by conventional dilatometry and in-situ optical microscopy respectively.

The constrained densification rate was greatly retarded compared with the free densification rate at the same density and the retardation increased with increasing density and temperature. As a result the apparent activation energy is much lower for constrained sintering $\left(135 \pm 20 \mathrm{~kJ} \mathrm{~mol}^{-1}\right)$ than for free sintering $\left(660 \pm 30 \mathrm{~kJ} \mathrm{~mol}^{-1}\right)$. This is opposite to what has been previously reported for constrained sintering of gold and silver films. The magnitude of the retardation, and its variation with density and temperature, cannot be accounted for by existing theories of constrained sintering. It is proposed that this is because the constrained microstructure (grain size and pore size and distribution) is not just a function of density, but depends on the detailed thermal history. In particular, the pores are larger and more widely separated in the constrained films sintered at the higher temperatures and densities.
\end{abstract}

Keywords Sintering, films, $\mathrm{ZrO}_{2}$, fuel cells, porosity. 


\section{$1 \quad$ Introduction}

Solid oxide fuel cells (SOFCs) are capable of converting chemical energy (from hydrogen or hydrocarbon fuels) into electrical energy with high efficiency and therefore have the potential to make a significant contribution to the reduction of greenhouse gas emissions. Many planar SOFC concepts have a supported thick film electrolyte with typical thickness in the range 5 $20 \mu \mathrm{m}$ in order to reduce the ohmic resistance loss associated with the electrolyte. These electrolyte films are typically fabricated by sintering a green powder layer that has been deposited on a substrate by screen printing, or a related method. There is a reasonably wide choice of electrolyte material [1], but the most common are yttria-stabilised zirconias. 8YSZ ( $8 \mathrm{~mol} \% \mathrm{Y}_{2} \mathrm{O}_{3}$ doped zirconia) has the cubic structure and the highest conductivity in this family, and is favoured by most SOFC developers. 3YSZ (3 mol \% $\mathrm{Y}_{2} \mathrm{O}_{3}$ doped zirconia), with the tetragonal structure, has a lower ionic conductivity, but better mechanical properties and is preferred for this reason by some developers [2].

Anode-supported electrolyte cells are usually fabricated by co-sintering the electrolyte and the anode support. This imposes a constraint on the sintering of each component and leads to stress and distortion during the sintering process [3]. However, during co-sintering there is some common shrinkage in the plane of the bi-layer composite and this relaxes the constraint somewhat. In other concepts (e.g. the integrated planar or segmented in series design of Rolls-Royce Fuel Cell Systems [4]) the substrate is effectively rigid. In such cases the electrolyte layer is fully constrained in its plane during sintering and shrinkage only occurs perpendicular to this plane (except within a distance of a few layer thicknesses of the layer edges).

This constrained sintering process is also a feature of many other ceramic processing technologies and is a topic of considerable fundamental interest. The constraint results in a tensile stress in the plane of the film that is just sufficient to oppose its tendency to shrink in 
this plane, were it not for the constraint, and this has two main consequences. The first is that the densification is retarded $[5,6]$ in comparison with an unconstrained case, and the second is that the in-plane tensile stress can cause crack-like defects and porous channels in the constrained film, or delamination from the substrate [7,8]. In a related publication [9] we have reported measurements of this sintering-induced stress for 3YSZ screen-printed films constrained by $3 \mathrm{YSZ}$ substrates. In the current paper we report a study of the constrained sintering kinetics of similar 3YSZ films. Although there are several experimental studies of the sintering kinetics and sintering-induced stresses in constrained films, as far as the authors are aware none of these studies has measured the sintering kinetics and sintering-induced stress on the same ceramic films.

A theory for constrained sintering based on viscous constitutive deformation equations was developed by Bordia and Scherer [10,11]. The relationship between the densification rate for a constrained film, $\dot{\rho}_{\text {constr }}$, and the unconstrained material, $\dot{\rho}_{\text {free }}$, is given by

$$
\frac{\dot{\rho}_{\text {constr }}}{\dot{\rho}_{\text {free }}}=\frac{\left(1+v_{p}\right)}{3\left(1-v_{p}\right)}
$$

where $v_{p}$ is the viscous Poisson's ratio. If $v_{p}<0.5$ then the constrained densification rate is lower than the unconstrained rate, and when $v_{p}=0$ the constrained densification rate is $1 / 3$ the unconstrained rate (i.e. the strain rate perpendicular to the film plane is equal to the unconstrained strain rate). According to this model, lower constrained densification rates imply negative viscous Poisson's ratio, which the authors consider to be unphysical. The viscous Poisson's ratio is a function of porosity and the details of the microstructural geometry.

In their seminal work on sintering kinetics of constrained films, Garino and Bowen [5] studied glass, zinc oxide and alumina powder films $100 \mu \mathrm{m}$ thick. They applied the viscous sintering model by first fitting the unconstrained sintering kinetics to obtain the key model 
parameters, which were then used to predict the constrained kinetics. They found that the viscous sintering model could explain the observed kinetics for the glass films, provided that the microstructure in the constrained film was assumed anisotropic (although electron microscopy of the films did not reveal any anisotropy). However, for the crystalline films the viscous model could not account for the influence of the constraint on the sintering kinetics. In particular the retardation showed a much larger inhibiting effect of the constraint at extended times than predicted by the theory, and the films appeared to reach a limiting density lower than the final density achieved in the unconstrained case. The authors suggested this was related to coarsening of the polycrystalline microstructure. They observed that the ceramic films tended to develop porous regions separated by dense regions which were not seen in the glass films (although the reason for such a difference in unclear). They also considered that grain growth would be unaffected by the constraint and therefore the ratio of grain growth rate to densification rate would be higher for the constrained films than for unconstrained sintering. Their model of this process could account for the constrained sintering kinetics, but unfortunately the degree of grain growth observed was significantly less than required for the model. Therefore the sintering kinetics of constrained ceramic films is not only not accounted for by the viscous sintering model, but is significantly influenced by differences in developing microstructure compared with the unconstrained case.

Similar studies have been reported for films of gold and silver circuit pastes. Choe et al. [12] found that the densification rate of gold films was also much slower than predicted by the viscous model and they too considered that this might be due to an increase in the ratio of grain growth to densification rates in the constrained films. However, they found that the observed grain sizes were not consistent with this mechanism. They estimated the activation energies from the sintering kinetics and found that there appeared to be a much lower 
activation energy (by approximately a factor of 2) for free sintering than for constrained sintering, which was suggested to imply a change in mechanism from grain boundary diffusion to lattice diffusion control. However, it seems unlikely that there could be such a dramatic change in transport mechanism for films sintered at the same temperature. Lin and Jean [13] found similar behaviour for silver films and their estimated the activation energies were approximately three times larger for constrained sintering than for unconstrained sintering. They also ascribed this to a change in sintering mechanism from grain boundary to lattice diffusion control.

More recently Guillon et al. [14] measured the constrained sintering kinetics of alumina films $20 \mu \mathrm{m}$ in thickness. Their results were similar to the above studies in that the constrained densification rate was slower than predicted by the viscous sintering model and that the constrained films appeared to have a limiting relative density that depended on temperature. They suggested that this was because of the development of anisotropy in the microstructure of the constrained films and a resulting modification of the isotropic viscous model was developed to include anisotropy in the microstructure $[15,16]$. They found anisotropic shrinkage in sinter-forging experiments on alumina compacts consistent with the theory. However, the theory is difficult to apply to constrained films because it requires two independently measured (or modelled) free strain rates and two viscous Poisson's ratios corresponding to in-plane and out-of-plane principal directions. Additionally, a related study [17] found that the retardation in the constrained densification was greater for thinner films (50 $\mu \mathrm{m}$ as opposed to $150 \mu \mathrm{m}$ ) and that the anisotropy in the microstructure was also greater, which supports the hypothesis that this anisotropy is responsible for the deviation of the experimental kinetics from the standard isotropic model. Therefore a second objective of the present study is to determine whether 3YSZ films behave in a similar way to the alumina films and whether there is any evidence for a change in the controlling mass transport 
mechanism (as suggested in the studies of gold and silver).

\section{$2 \quad$ Materials and methods}

\subsection{Dilatometry}

Three different types of sintering kinetic measurement were made: unconstrained sintering of powder compacts by conventional dilatometry; unconstrained sintering of free-standing film specimens by image analysis; and constrained sintering of screen printed films in a high sensitivity optical dilatometer.

Conventional dilatometry was carried out in a push-rod dilatometer (Netzsch DIL 402 E). Two different types of experiment were carried out. The first type was at different controlled heating rates $\left(3-30 \mathrm{~K} \mathrm{~min}^{-1}\right)$ in order to obtain the activation energy for unconstrained densification. The final density was calculated from the mass of the specimen and its final dimensions.

To measure the sintering kinetics of the unconstrained films, a fragment of a film tape cast from the screen printing ink was supported vertically in a furnace that had an observation window. In-plane shrinkage was monitored using a long-distance microscope (Infinity K2) and camera [9]. Digital images were recorded periodically and subsequently analysed to quantify dimensional changes. The linear shrinkage was calculated by measuring the distance between two sharp features on the edges of the areal view of the specimen and assuming that the shrinkage was isotropic. The final density was measured by analysis of scanning electron microscope (SEM) images and the density during sintering calculated from that reference point using the shrinkage measurements.

Constrained sintering of individual constrained films was measured using an optical dilatometer and this is now described in detail. The experimental studies of constrained sintering kinetics referred to in the Introduction all used optical methods. Garino and Bowen 
[5] used a reflective bridge which had one end resting on the film surface and the other on a fixed reference which was also reflective. A narrow light beam was incident vertically and generated two reflected beams from the two reflective surfaces. As the film sintered the bridge tilted and the angle between the two beams changed. The beams were incident on a screen and their separation there was measured manually. The same type of arrangement was employed in the studies of gold and silver films [12,13]. Guillon et al. [14] developed a different optical method in which a rocking arm (bridge) provided intermediate magnification and the displacement of the arm was measured using an optical micrometer. Their apparatus was applied to films $20 \mu \mathrm{m}$ thick (whereas the green films in the earlier studies were in the range $50-100 \mu \mathrm{m}$ ) and had a claimed resolution of $50 \mathrm{~nm}$. The method used in the present study is similar to the optical lever methods, but in a horizontal configuration, and adapted to green films typically $10 \mu \mathrm{m}$ thick.

The general arrangement is illustrated in Figure 1a. The specimen was supported on a cylindrical horizontal alumina rod, which was clamped in a "V" block. A flat platform was machined at the end of the rod to support the specimen. The moveable tube furnace had end caps with windows to allow the passage of the light beams which were generated by a solid state red laser (Global Laser, Premier-LC, $635 \mathrm{~nm}$ ). After exiting the furnace tube window the light beam was incident upon a $1 \mathrm{~cm}^{2} \mathrm{X}-\mathrm{Y}$ photo-detector (Hamamatsu S5991-01) to record its position. The deflection of the beam in the $x$-direction is related to the tilt angle of the bridge, $\phi$, by

$$
x=2 L \tan \theta \sin \phi \cos \phi
$$

where $\theta$ is the angle between the beam and the horizontal. For small $\phi$ this gives the magnification

$$
\frac{d x}{d h}=\frac{2 L \tan \theta}{l}=2 \frac{d}{l}
$$


where $d$ and $l$ are defined in Figure 1. In a typical experiment $l=3 \mathrm{~mm}$ and $d=60 \mathrm{~mm}$ giving a magnification of 40 . Since the photo-detector resolution was $2 \mu \mathrm{m}$, this gives a resolution of approximately $50 \mathrm{~nm}$ for measuring changes in film thickness, similar to that in the apparatus in Guillon et al. [14]. In principle the magnification for the bridge tilting parallel to the beam is much higher; the $y$ displacement being

$$
\frac{d y}{d h}=2 \frac{L}{l}
$$

Since L is approximately $45 \mathrm{~cm}$ this gives a magnification of 300 . However, it was found that the arrangement was much more unstable with respect to drift in this orientation and so the lower sensitivity arrangement was preferred. The bridge was a single crystal of cubic zirconia (dimensions: $15 \times 7 \times 1 \mathrm{~mm}$ ) with the top face flat and polished. On the opposite face were three hemispherical contact points as shown in Figure 1. Two points rest on the film surface and one on the substrate to give a stable contact. The contact points were made by grinding cubic zirconia spheres ( $3 \mathrm{~mm}$ diameter) to hemispheres and attaching these to the bridge using a paste of fine $8 \mathrm{YSZ}$ powder followed by sintering at $1400{ }^{\circ} \mathrm{C}$ for $3 \mathrm{~h}$.

In order to improve the mechanical stability of the arrangement the specimen was supported on a 3 YSZ ring. The ring had three points on one side making contact with the specimen holder and three on the other side making contact with the specimen. The 3-point support of both the specimen and the bridge ensured that there was no rocking of the arrangement caused by the surfaces in contact not being perfectly flat.

The beam position co-ordinates were recorded by the detector at a frequency of $4 \mathrm{~Hz}$ and typically averaged over consecutive periods of 6 minutes to reduce noise. Dummy runs on non-sintering specimens in the arrangement shown in Figure 1, showed that there was some small residual drift in the $x$ signal that was proportional to a larger drift in the $y$ signal. The drift was only significant during the non-isothermal periods of an experiment. Therefore in each run with sintering specimens, any observed drift in the $y$ signal was used to apply a drift 
correction to the $x$ signal. The displacement data over the whole of an experimental run were calibrated against the actual film thickness change measured before and after sintering using an interference microscope (ZYGO NewView, Middlefield, USA). The final densities of films sintered at the higher temperatures were estimated from image analysis of SEM images of their final structure and their final film thickness was also confirmed by SEM to be consistent with the interference microscope measurements. The film green density was then calculated from the final density and the measured change in film thickness.

\section{$2.2 \quad$ Specimens}

The film and substrate were chosen to be the same composition to ensure that no stresses would be generated by thermal expansion differences between the film and substrate. The 3YSZ powder used to prepare the screen-printing ink and substrates was supplied by MEL Chemicals, UK. Its particle size distribution was measured by light scattering and its parameters were: $\mathrm{d}_{10}=0.38 \mu \mathrm{m} ; \mathrm{d}_{50}=0.50 \mu \mathrm{m}$; and $\mathrm{d}_{90}=0.77 \mu \mathrm{m}$. The specific surface area was $6.9 \mathrm{~m}^{2} \mathrm{~g}^{-1}$.

For sintering dilatometry of the constrained films using the optical dilatometer, thick substrates were prepared. Powder compacts were produced by uniaxial die-pressing at 150 $\mathrm{MPa}$ and then sintered at $1400^{\circ} \mathrm{C}$ for $2 \mathrm{~h}$ to give discs $36 \mathrm{~mm}$ diameter and $0.7 \mathrm{~mm}$ thickness. The surfaces of the discs were ground to be flat and parallel and then one face was polished to $1 \mu \mathrm{m}$ diamond finish. YSZ layers were deposited on the substrates by screen printing (165 mesh screen and $2.5 \mathrm{~mm}$ gap) so as to cover half the substrate area as illustrated in Figure 1, and the layers were oven dried at $120^{\circ} \mathrm{C}$. At this stage the films were in the thickness range $10-13 \mu \mathrm{m}$.

For measurement of sintering of unconstrained free-standing films, specimens approximately 40 - $50 \mu \mathrm{m}$ thick were tape cast onto Mylar substrates using the same inks as used for screen printing and dried in the same way as the screen-printed layers. In addition, cylindrical 
specimens (approximate dimensions $6 \mathrm{~mm}$ diameter x $5 \mathrm{~mm}$ length) were prepared for conventional dilatometry by die pressing dry powders at $150 \mathrm{MPa}$ followed by isostatic pressing at 300MPa.

\section{Results}

\subsection{Unconstrained sintering}

Figure 2 shows the linear shrinkage curves of bulk specimens sintered at different constant heating rates. The curves were differentiated to give the densification rates at densities of 75 , 80 and $85 \%$ (which are reached at different temperatures for different heating rates). The results are plotted in Arrhenius form in Figure 3. The corresponding activation energies are also shown (Fig.3) and are in the range $640-680 \mathrm{~kJ} \mathrm{~mol}^{-1}$. The average activation energy for sintering is thereby determined to be $660 \pm 20 \mathrm{~kJ} \mathrm{~mol}^{-1}$.

According to $\mathrm{Su}$ and Johnson [18] for a given powder and green-body process, the sintering behaviour can be predicted by a master sintering curve. The concept of a master sintering curve is based on the premise that the density of a sintering body is a unique function of its thermal history (i.e. all thermal histories can be reduced to a common relationship with relative density) which is expressed by the function $\Theta$ :

$$
\Theta(t, T)=\int_{0}^{t} \frac{1}{T} \exp \left(\frac{-Q_{s}}{R T}\right) d t
$$

where $Q_{s}$ is the activation energy for sintering. For a constant heating rate $c$ this becomes

$$
\Theta(t, T)=\frac{1}{c} \int_{T_{o}}^{T} \frac{1}{T} \exp \left(\frac{-Q_{s}}{R T}\right) d T
$$

The relationship between the relative density, $\rho$, and $\Theta$ is known as the master sintering curve. In order to create the master sintering curve, $\rho$ obtained at different heating rates is plotted against $\Theta$ and the value of $Q_{s}$ is adjusted until all the data fall on a single curve. The best fit was determined by minimising the RMS deviation function 


$$
\Delta(\operatorname{Ln} \Theta)=\int_{\rho_{0}}^{\rho_{f}} \frac{\left(\sum_{i=1}^{N}\left(\operatorname{Ln} \Theta_{i}-\operatorname{Ln} \Theta_{a v}\right)^{2}\right)^{\frac{1}{2}}}{N\left(\rho_{0}-\rho_{f}\right)} d \rho
$$

where the summation is over the different heating rates and $\rho_{0}$ and $\rho_{f}$ are the green and final densities. Figure 4 shows this function plotted against $Q_{s}$, from which it can be seen that the best value of the activation energy is $700 \pm 50 \mathrm{~kJ} \mathrm{~mol}^{-1}$ in good agreement with the results from the Arrhenius plots in Figure 3. Figure 5 shows the data plotted as a master sintering curve using this value of $Q_{s}$. A similar analysis for a different 3 YSZ powder reported by Mazaheri et al. [19] gave an activation energy of $485 \pm 12 \mathrm{~kJ} \mathrm{~mol}^{-1}$, which is significantly lower than the present value. However, Matsui et al. [20] report an activation energy of 683 $\mathrm{kJ} \mathrm{mol}^{-1}$ from isothermal sintering experiments, in good agreement with the present results. Furthermore, this magnitude of activation energy is similar to that $\left(500 \mathrm{~kJ} \mathrm{~mol}^{-1}\right)$ deduced by Chokshi [21] from an analysis of creep controlled by grain boundary diffusion in 3 YSZ.

The unconstrained densification of the films cast from the screen printing ink, and measured using the long focus microscope, is compared with that of a bulk specimen at a constant heating rate of $3 \mathrm{~K} \mathrm{~min}^{-1}$ in Figure 6. Although there are some differences, the behaviour is sufficiently similar to conclude that the densification of the bulk specimens is representative of the unconstrained screen-printed films.

\subsection{Constrained sintering}

The densification of the constrained films at a heating rate of $20 \mathrm{~K} \mathrm{~min}^{-1}$ is compared with that of an unconstrained bulk specimen at the same heating rate in Figure 6. The large degree of retardation caused by the constraint is evident.

In order to study the retardation in greater detail it was necessary to compare the densification behaviour under isothermal conditions. The isothermal densification kinetics (after heating

to the isothermal temperature at $20 \mathrm{~K} \mathrm{~min}^{-1}$ ) for the constrained films are shown in Figure 7. 
However, because of the large retardation caused by the constraint it was not possible experimentally to obtain a good overlap of densities between the isothermal densification kinetics for both constrained and free specimens. Therefore the isothermal kinetics for free sintering were calculated using the master sintering curve. The constrained isothermal densification rates are much slower than the unconstrained ones as illustrated by the example shown in Figure 8 . The raw data for constrained sintering were smoothed by fitting to polynomials (of order 4 to 6 ) to remove the noise which is evident in Figure 7. All the data within the range $0-180$ mins were included in the fitting, except for the experiments at 1100 ${ }^{\circ} \mathrm{C}$ and $1150{ }^{\circ} \mathrm{C}$, where the initial data $\left(0-15 \mathrm{~min}\right.$ for the case of $1100^{\circ} \mathrm{C}$ and $0-10 \mathrm{~min}$ for the case of $1150^{\circ} \mathrm{C}$ ) were excluded for the fitting because of excessive noise in this region.

By differentiating the densification curves, such as those in Figure 8, the relative rates of constrained and free densification were calculated at different densities. The result is shown in Figure 9. (Note that the data for $1350^{\circ} \mathrm{C}$ at the highest densities are not reliable because both constrained and free densification rates are very low in this region.) There is a clear trend for the retardation caused by the constraint to become larger as both the temperature and density increase. However, it is not clear which of these is controlling as they are strongly correlated.

Figure 10 shows an Arrhenius plot of the constrained densification rates at different relative densities. The range of densities is quite narrow because there is limited overlap at a suitable range of temperature. Although the data are scattered it is clear that the average apparent activation energy is very low (approximately $135 \pm 20 \mathrm{~kJ} \mathrm{~mol}^{-1}$ ) which is much lower than for free sintering. The reason for this is that the retardation caused by the constraint increases with increasing temperature.

\section{Discussion}

The experimental results reveal the following key observations: first, the apparent activation 
energy for constrained sintering is much lower than for free sintering; second, the retardation caused by the constraint is larger than predicted by the simple viscous theory; and, third, the retardation increases as density (or temperature) increases. Here we suggest that all these features are the result of the constraint producing a major modification to the microstructure of the densifying film in comparison with the freely sintering body at the same density.

From Equation 1 the lower bound of $\frac{\dot{\rho}_{\text {constr }}}{\dot{\rho}_{\text {free }}}$ is $1 / 3$ according to the simple viscous theory, whereas all the experimental measurements (Figure 9) fall below this value. This has been observed also for alumina films and is attributed to the development of anisotropy in the microstructure of the constrained film ${ }^{15}$. Recently Li et al. [22] developed a theory of constrained sintering based upon anisotropic constitutive viscous deformation equations. Application of the theory to a constrained film enables a simple way of calculating $\frac{\dot{\rho}_{\text {constr }}}{\dot{\rho}_{\text {free }}}$ when the relative density is less than 0.85 . The calculation involves only one adjustable parameter, $\eta^{*}$, which characterises the contribution of grain boundary sliding to viscous deformation and controls the viscous Poisson's ratio through the relationship

$$
v_{p}=0.25-\frac{1.025 \eta^{*}|E|}{3.352 E^{2}+0.838 \eta^{*}|E|}
$$

$E$ is the average strain in the film and is related to the relative density by $\rho=\rho_{0} \exp (-3 E)$. The ratio of constrained to free densification rates calculated in this way is also shown in Figure 9. The calculated curve is for $\eta^{*}=0$ (which from Equation 8 corresponds to $v_{p}=$ 0.25 ), but the curve is not particularly sensitive to the value of $\eta^{*}$ in the range 0 to 0.01 ( $\mathrm{Li}$ et al. deduced a value of 0.005 in their analysis of sintering of alumina.) Although this theory in Figure 9 predicts greater retardation than does the isotropic viscous theory, it does not reproduce the trend with relative density seen in the present experiments. Furthermore, this approach predicts that the apparent activation energies for constrained and free sintering are 
equal, which we do not observe in the experiments.

One possible reason for this is that the simplified version of the anisotropic viscous deformation theory does not properly capture the effects of grain growth. An implicit assumption is that grain size is only a function of density and for alumina this was supported by experimental observations. However, this is not expected to be generally the case, because the dependence of grain size on time and temperature is likely to be different from that of density on the same parameters. In particular, it might be expected that the slower densification kinetics of the constrained film require a longer time, at a give temperature, to reach a given density and therefore there is more opportunity for grain growth. If we assume that grain growth is a function of time and temperature, rather than density, then the grain relative grain sizes for constrained and free cases, at a given density, can be estimated from grain growth data and hence their effects on relative densification rates assessed. The grain sizes were measured on high resolution SEM micrographs using the linear intercept method. Grain growth follows the following kinetic equation [19]

$$
G_{t}^{m}-G_{o}^{m}=m \int_{0}^{t} k_{o} \exp \left(-\frac{Q_{G}}{R T}\right) d t
$$

where $G$ is the grain size, the exponent $m$ is typically between 2 and 4 , and $Q_{G}$ is the activation energy for grain growth. When $T=$ constant (i.e. isothermal), Equation 9 can be simplified as $G_{t}^{m}-G_{o}^{m}=C(T) t$, where $C$ is a constant that depends on $T$. The grain growth data from isothermal sintering at $1350^{\circ} \mathrm{C}$ were fitted to this equation and it was found that $m$ $=4$ and $G_{0}=0.17 \mu \mathrm{m}$. Equation 9 can also be rewritten as:

$$
G_{t}^{m}-G_{o}^{m}=m \theta_{G}
$$

with $\quad \theta_{G}=\int_{0}^{t} k_{o} \exp \left(-\frac{Q_{G}}{R T}\right) d t$

The relationship between $G_{t}$ and $\theta_{G}$ can be regarded as a grain growth master curve. Our 
experimental measurements for specimens sintered at different times and temperatures are shown fitted to this curve in Figure 11 from which the activation energy was determined as: $Q_{G}=330 \mathrm{~kJ} \mathrm{~mol}^{-1}$.

This activation energy is somewhat smaller than the value $550 \mathrm{kJmol}^{-1}$ reported by Nieh and Wadsworth [23]. Assuming that the densification rate is proportional to $G^{-4}$, we have estimated the ratio of constrained to free densification rates at $80 \%$ relative density to be 0.56 at $1250^{\circ} \mathrm{C}$ and 0.39 at $1300^{\circ} \mathrm{C}$. Thus, this process gives an increase in relative retardation due to the constraint with increasing temperature as observed in the experiments, but it is not as big an effect as observed and cannot be responsible on its own for the observed retardation in densification rate.

It is now well-established that constrained sintering leads to anisotropy and heterogeneity in the microstructure and in another publication we have reported anisotropy and heterogeneity in the microstructure of 3 YSZ films during constrained sintering [24]. Of relevance to the present work is the observation that the constraint leads to a marked increase in the mean pore size and even to growth of pores larger than a critical size, which was deduced in the model to be 12 times the grain size [24]. This leads to heterogeneity in the pore size distribution in that many pores become much larger than the grains and are separated by relatively dense sintered regions. Some pores are abnormally large: $>20$ times the grain size as illustrated in Figure 12. The number density of such abnormally large pores is about 100 $\mathrm{mm}^{-2}$, which is very small when compared to that of the background of small (normal) pores (of the order of $10^{6} \mathrm{~mm}^{-2}$ ). Nevertheless, the total volume of such large pores is comparable to that of the background small pores. We define the pore size heterogeneity as the volume ratio of the abnormally large pores over that of the normal pores. From quantitative analysis of the microstructure, the pore size heterogeneity was calculated and is plotted as a function of density in Figure 13. It can be seen that the heterogeneity increases very rapidly with 
density. Since the abnormally large pores are typically larger than the critical size, they tend to grow in size instead of shrink [24]. Therefore the heterogeneity of the pore size distribution may account for a major part of the observed large retardation at higher temperature (density).

Since grain growth and pore heterogeneity both lead to reduction in the ratio of constrained to free densification rates at a given relative density, they lead to a reduction in the apparent activation energy for constrained sintering, as observed in the present experiments, because the retardation is greater the higher the temperature. This change in apparent activation energy does not imply a change in the rate controlling process, which is grain boundary diffusion in both cases, but is a consequence of the different evolution of the microstructure in constrained and free cases. This decrease in apparent activation energy is the opposite of that reported for the constrained gold and silver films, which implies that the evolution of the microstructure is qualitatively different for the constrained metal films.

\section{Conclusions}

An optical dilatometer has been constructed to measure the sintering of films constrained by a substrate and applied to $3 \mathrm{YSZ}$ films on $3 \mathrm{YSZ}$ substrates. The free sintering of unconstrained specimens made from the same powder could be described by a master sintering curve. The constrained densification rate is greatly retarded compared with the free densification rate at the same density and the retardation increases with increasing density and temperature. As a result the apparent activation energy is much lower for constrained sintering $\left(135 \pm 20 \mathrm{~kJ} \mathrm{~mol}^{-1}\right)$ than for free sintering $\left(660 \pm 30 \mathrm{~kJ} \mathrm{~mol}^{-1}\right)$. This is opposite to what has been previously reported for constrained sintering of gold and silver films. The magnitude of the retardation cannot be accounted for by the isotropic viscous sintering theory, nor can its variation with density and temperature be explained by a simplified version of anisotropic sintering theory. It is proposed that this is due to the different 
evolution of the constrained and free microstructures. The constrained microstructure (grain size and pore size and distribution) is not just a function of density, but depends on the detailed thermal history. In particular, the pores are larger and more widely separated in the constrained films sintered at the higher temperatures and densities.

\section{Acknowledgements}

The authors are grateful to colleagues at Rolls-Royce Fuel Cell Systems for helpful discussions and assistance with screen printing. We also wish to thank Prof. J. Rödel and Dr.

O. Guillon for their help in allowing us to use the optical dilatometer at the University of Darmstadt. This research was carried out as part of the UK Supergen consortium project on "Fuel Cells: Powering a Greener Future". The Energy Programme is an RCUK cross-council initiative led by EPSRC and contributed to by ESRC, NERC, BBSRC and STFC. 


\section{References}

1 Kharton VV, Marques FMB, Atkinson A. Transport properties of solid oxide electrolyte ceramics: a brief review. Solid State Ionics 2004;174:135-149.

2 Malzbender J, Steinbrech RW. Fracture test of thin sheet electrolytes for solid oxide fuel cells. J. Eur. Ceram. Soc. 2007;27: 2597-2603.

3 Steinbrech RW, Caron A, Blass G, Dias F. Influence of sintering characteristics on component curvature of electrolyte-coated anode substrates. In: Stimming U, Singhal SC, Tagawa H, Lehnert W, editors. Proceedings of SOFC V, Electrochemical Society 1997 p. 727-736.

4 Costamagna P, Selimovic A, Del Borghi M, Agnew G. Electrochemical model of the integrated planar solid oxide fuel cell (IP-SOFC). Chemical Engineering Journal 2004;102:61-69.

5 Garino TJ, Bowen HK. Kinetics of constrained-film sintering. J. Am. Ceram. Soc. $1990 ; 73: 251-257$.

Zhao Y, Dharani LR. Theoretical-model for the analysis of a ceramic thin-film sintering on a non-sintering substrate. Thin Solid Films 1994;245:109-114. Jagota A, Hui CY. Mechanics of sintering thin-films 2: Cracking due to self-stress. Mechanics of Materials 1991;11:221-234.

Bordia RK, Jagota A. Crack-growth and damage in constrained sintering films. J. Am. Ceram. Soc. 1993;76:2475-2485.

Atkinson A, Kim J-S, Rudkin RA, Taub S, Wang X. Stress induced by constrained sintering of 3 YSZ films measured by substrate creep. J. Am. Ceram. Soc. 2010; no. doi: $10.1111 / \mathrm{j} .1551-2916.2010 .04160 . \mathrm{x}$ 
Bordia RK, Scherer GW. Constrained sintering-I, constitutive model for a sintering body. Acta metallurgica 1988;36:2393-2298. Bordia RK, Scherer GW. On constrained sintering-II, Comparison of constitutive models. Acta Metallurgica 1988;36:2399-2409. Choe JW, Calata JN, Lu GQ. Constrained-film sintering of a gold circuit paste. Journal of Materials Research 1995;10:986-994. Lin Y-C, Jean J-H. Constrained sintering of silver circuit paste. J. Am. Ceram. Soc. 2004;87:187-191.

Guillon O, Aulbach E, Rodel J, Bordia RK. Constrained sintering of alumina thin films: Comparison between experiment and modelling. J. Am. Ceram. Soc. 2007;90:1733-1737. Bordia RK, Zuo R, Guillon O, Salamone SM, Rödel J. Anisotropic constitutive laws for sintering bodies. Acta Materialia 2006;54:111-118. Guillon O, Nettleship I, Microstructural characterization of alumina films during constrained sintering, J. Am. Ceram. Soc. 2010; 93: 627-629.

Guillon O, Krauß S, Rödel J. Influence of thickness on the constrained sintering of alumina films. J. Eur. Ceram. Soc. 2007;27:2623-2627.

$\mathrm{Su}$ H, Johnson DL. Master sintering curve: A practical approach to sintering. J. Am. Ceram. Soc. 1996;79:3211-3217. Mazaheri M, Simchi A, Dourandish M, Golestani-Fard F. Master sintering curves of nanoscale 3Y-TZP powder compacts. Ceramics International 2009;35:547-554. Matsui K, Matsumoto A, Uehara M, Enomoto N, Hojo J. Sintering kinetics at isothermal shrinkage: Effect of specific surface area on the initial sintering stage of fine zirconia powder. J. Am. Ceram. Soc. 2007;90:44-49. 
Chokshi AH. Diffusion, diffusion creep and grain growth characteristics of nanocrystalline and fine-grained monoclinic, tetragonal and cubic zirconia. Scripta Materialia 2003;48:791-796.

22 Li F, Pan J, Guillon O, Cocks A. Predicting sintering deformation of ceramic film constrained by rigid substrate using anisotropic constitutive law. Acta Materialia 2010;58:5980-5988.

23

Nieh TG, Wadsworth J. Superelastic behaviour of a fine-grained, yttria-stabilized, tetragonal zirconia polycrystal (Y-TZP), Acta Metallurgica et Materialia 1990;38:1121-1133.

Wang X, Atkinson A. Microstructure evolution in thin zirconia films: Experimental observation and modelling, Acta Materialia 2011; 59:2514-2525. 


\section{Figure captions}

Figure 1 Schematic views of a) the optical dilatometer b) the bridge and specimen geometry and c) the specimen support ring.

Figure 2 Free sintering shrinkage curves for bulk powder specimens at different heating rates.

Figure 3 Arrhenius plots of densification rate for bulk unconstrained sintering at different densities (corresponding to different constant heating rates).

Figure 4 RMS deviation of dilatometry data, when plotted as a master sintering curve, as a function of activation energy.

Figure 5 Master sintering curve for bulk free sintering plotted for 4 different heating rates and assuming activation energy of $700 \mathrm{~kJ} \mathrm{~mol}^{-1}$.

Figure 6 Constant heating rate sintering curves comparing constrained and unconstrained specimens.

Figure 7 Isothermal densification of constrained films.

Figure 8 An example (at $1250^{\circ} \mathrm{C}$ ) comparing the isothermal densification kinetics of the constrained and free specimens.

Figure 9 The ratio of constrained to free densification rates as a function of density at different isothermal temperatures.

Figure 10 Arrhenius plot of the constrained densification rates at different densities.

Figure 11 Master curve for grain growth in $3 \mathrm{YSZ}$.

Figure 12 Examples of the microstructure after constrained sintering at $1350^{\circ} \mathrm{C}$ for $1 \mathrm{~h}$ :

a) film cross section; b) top surface.

Figure 13 Heterogeneity of the pore distribution (volume ratio of the abnormally large pores over that of normal pores) as a function of density of the constrained film. 


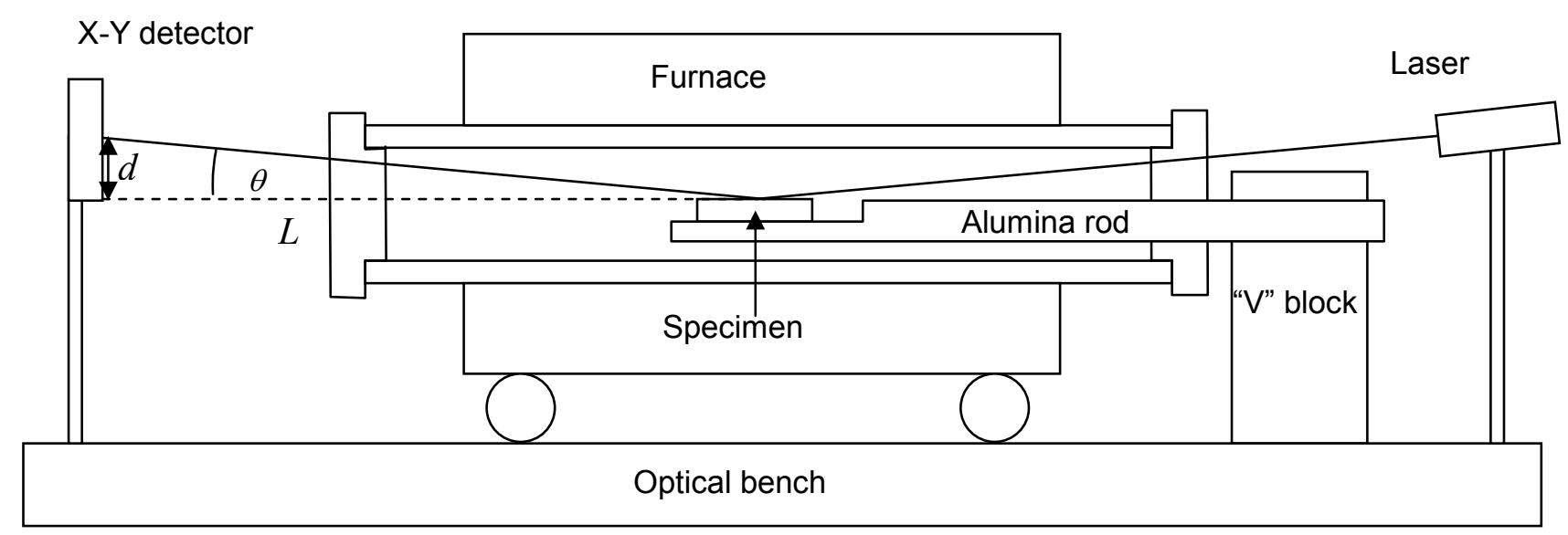

a)
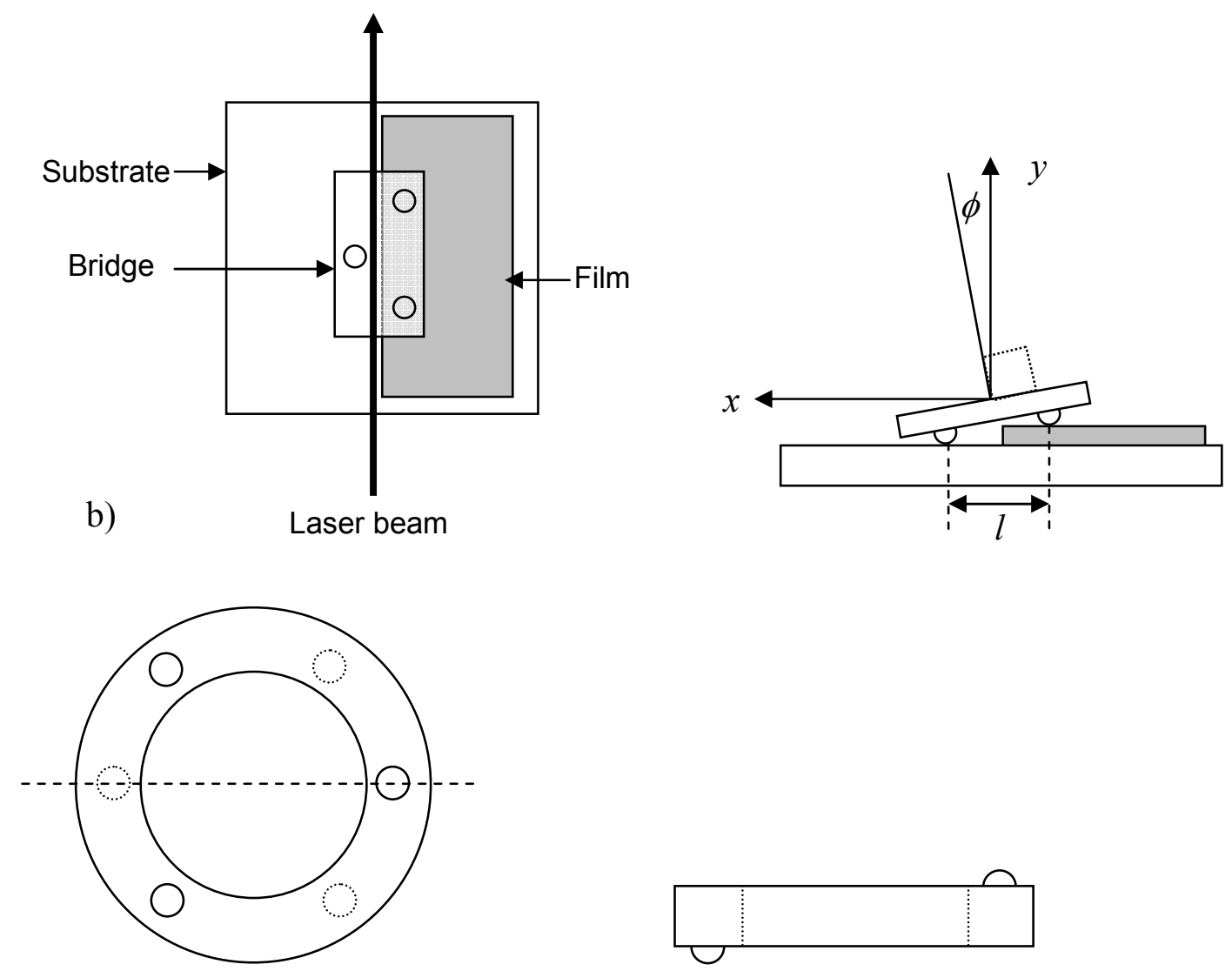

c)

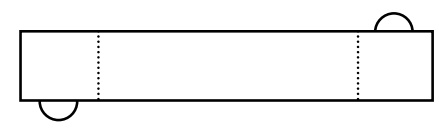

Figure 1 Schematic views of a) the optical dilatometer b) the bridge and specimen geometry and c) the specimen support ring. 


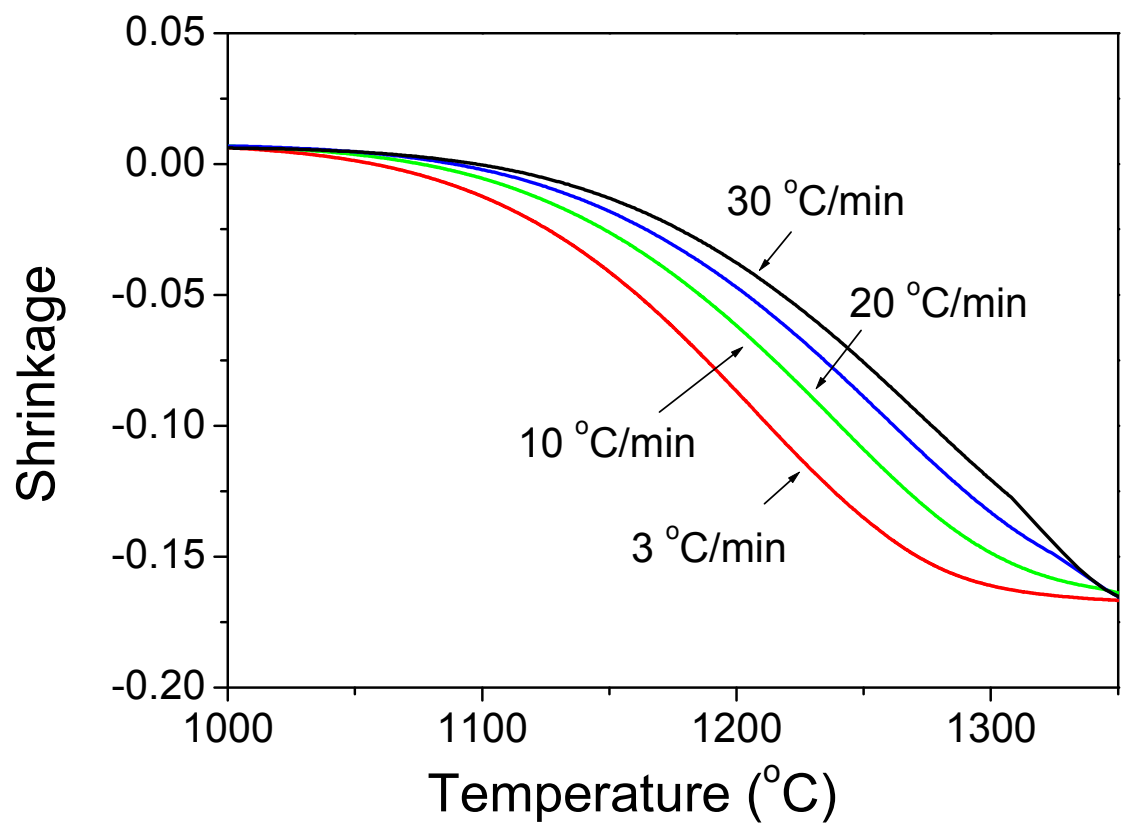

Figure 2 Free sintering shrinkage curves for bulk powder specimens at different heating rates. 


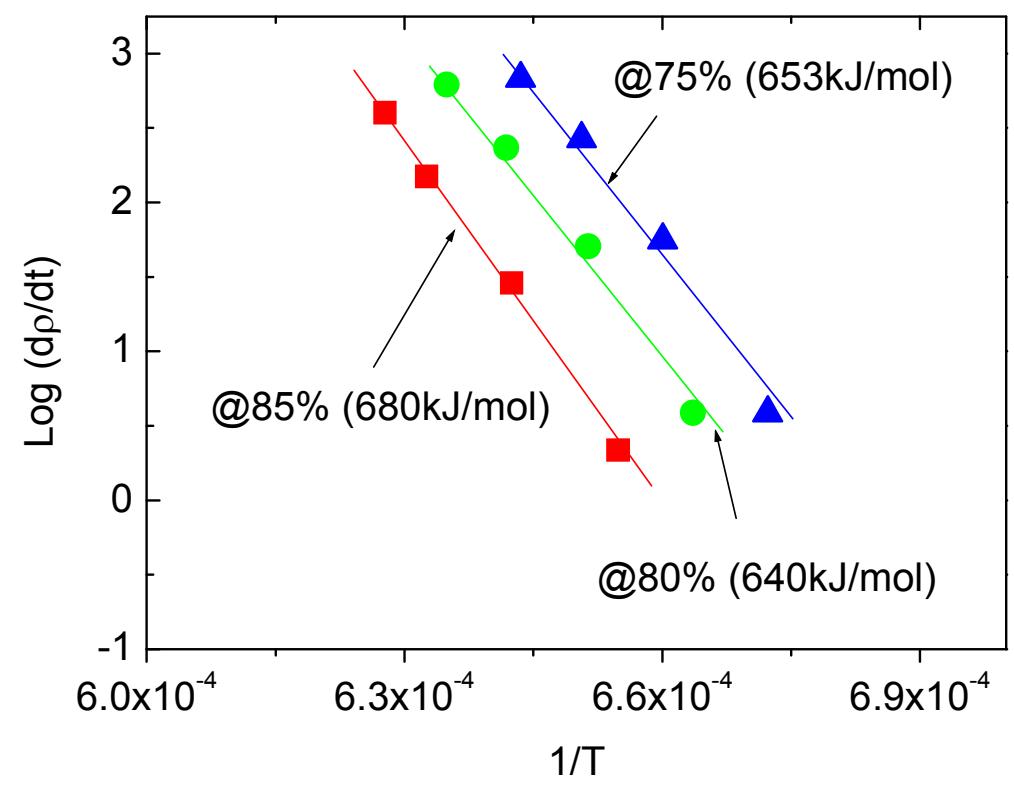

Figure 3 Arrhenius plots of densification rate for bulk unconstrained sintering at different densities (corresponding to different constant heating rates). 


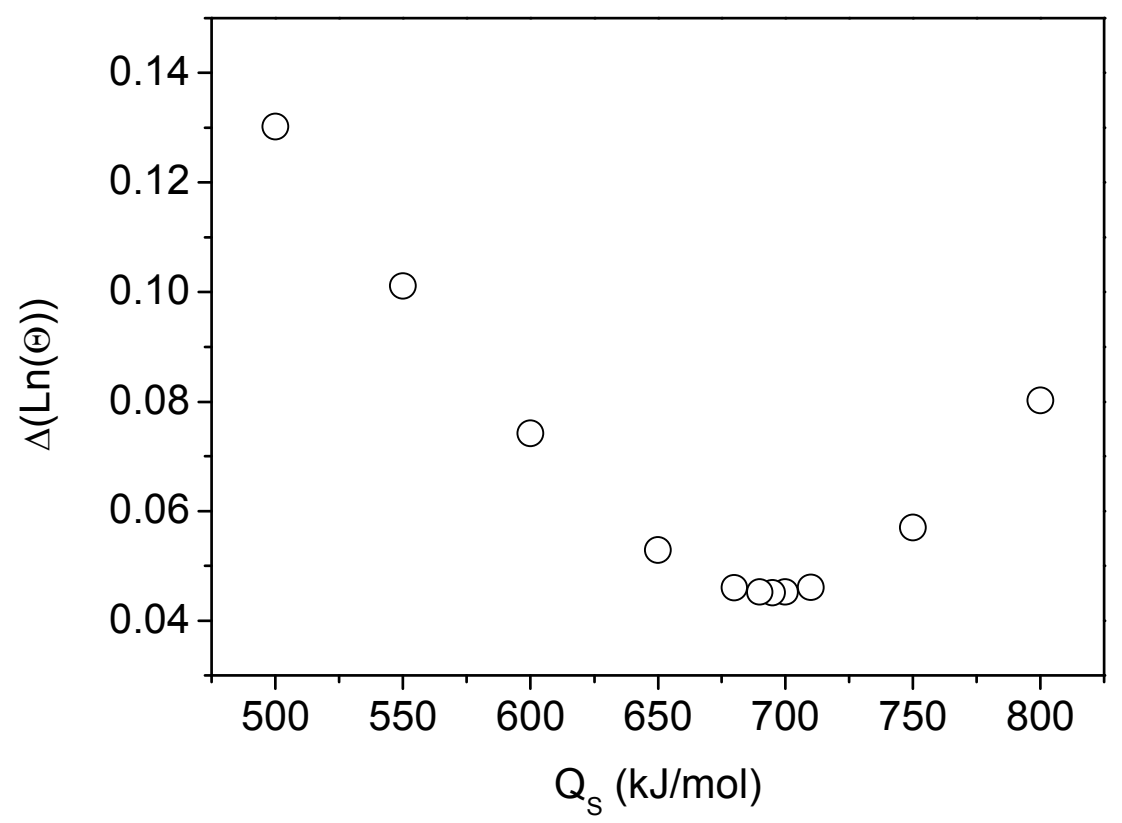

Figure 4 RMS deviation of dilatometry data, when plotted as a master sintering curve, as a function of activation energy. 


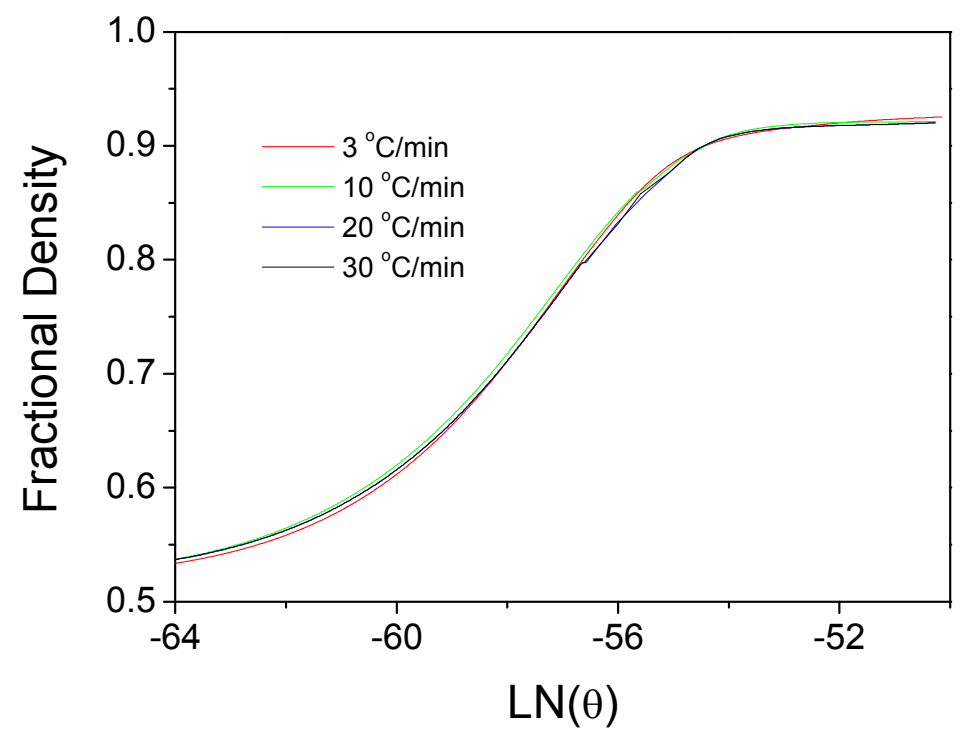

Figure 5 Master sintering curve for bulk free sintering plotted for 4 different heating rates and assuming activation energy of $700 \mathrm{~kJ} \mathrm{~mol}^{-1}$. 


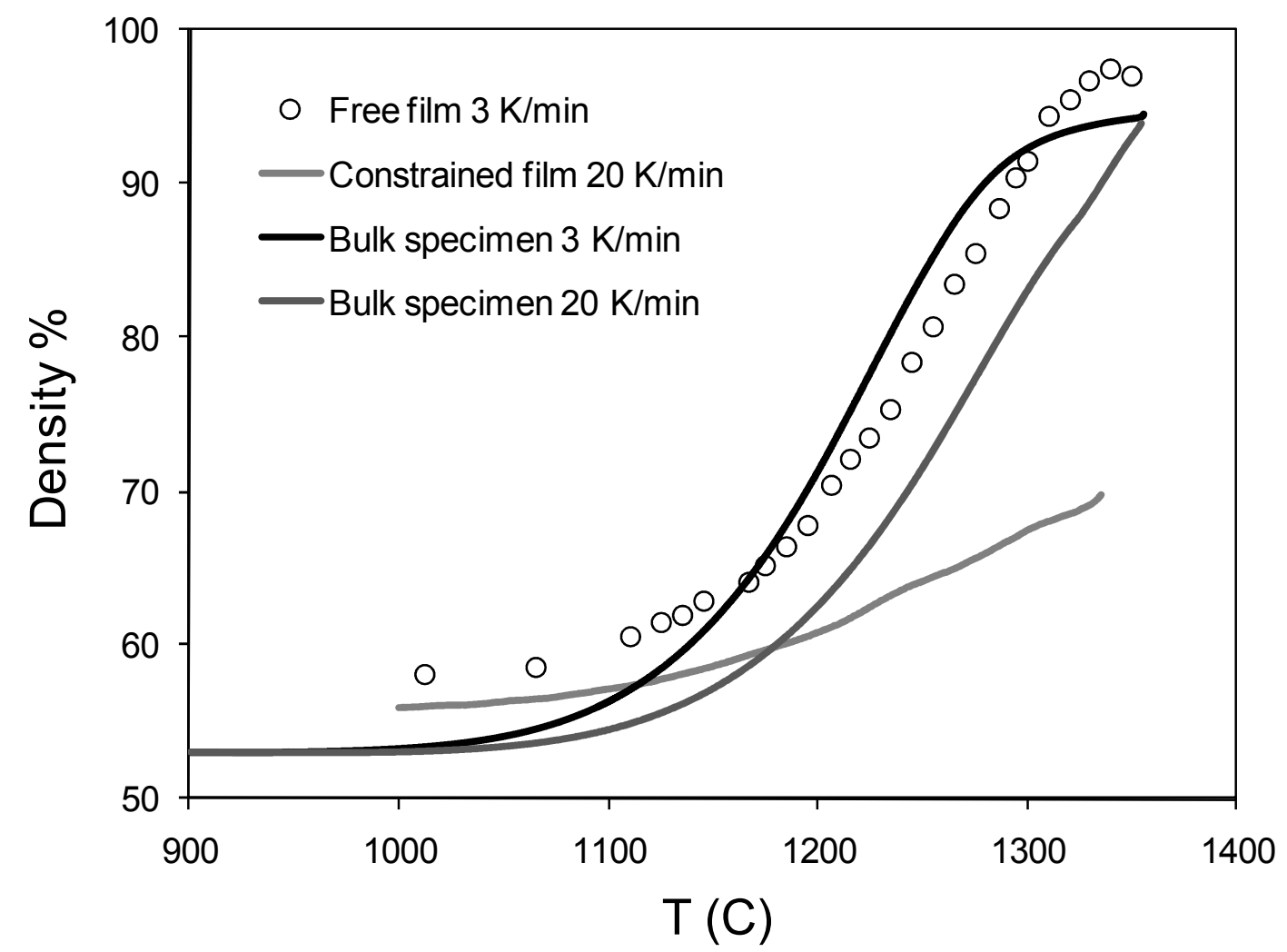

Figure 6 Constant heating rate sintering curves comparing constrained and unconstrained specimens. 


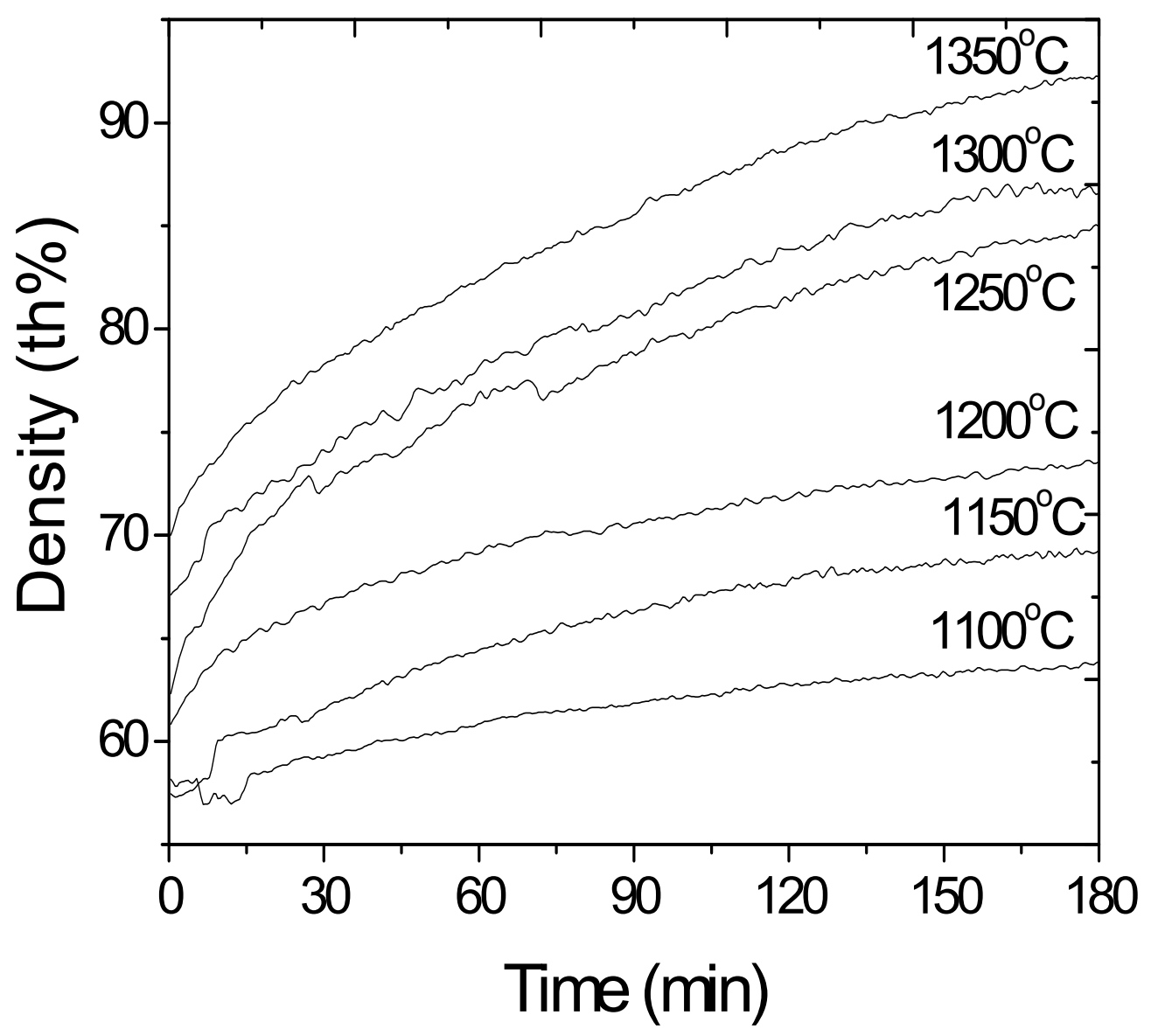

Figure 7 Isothermal densification of constrained films. 


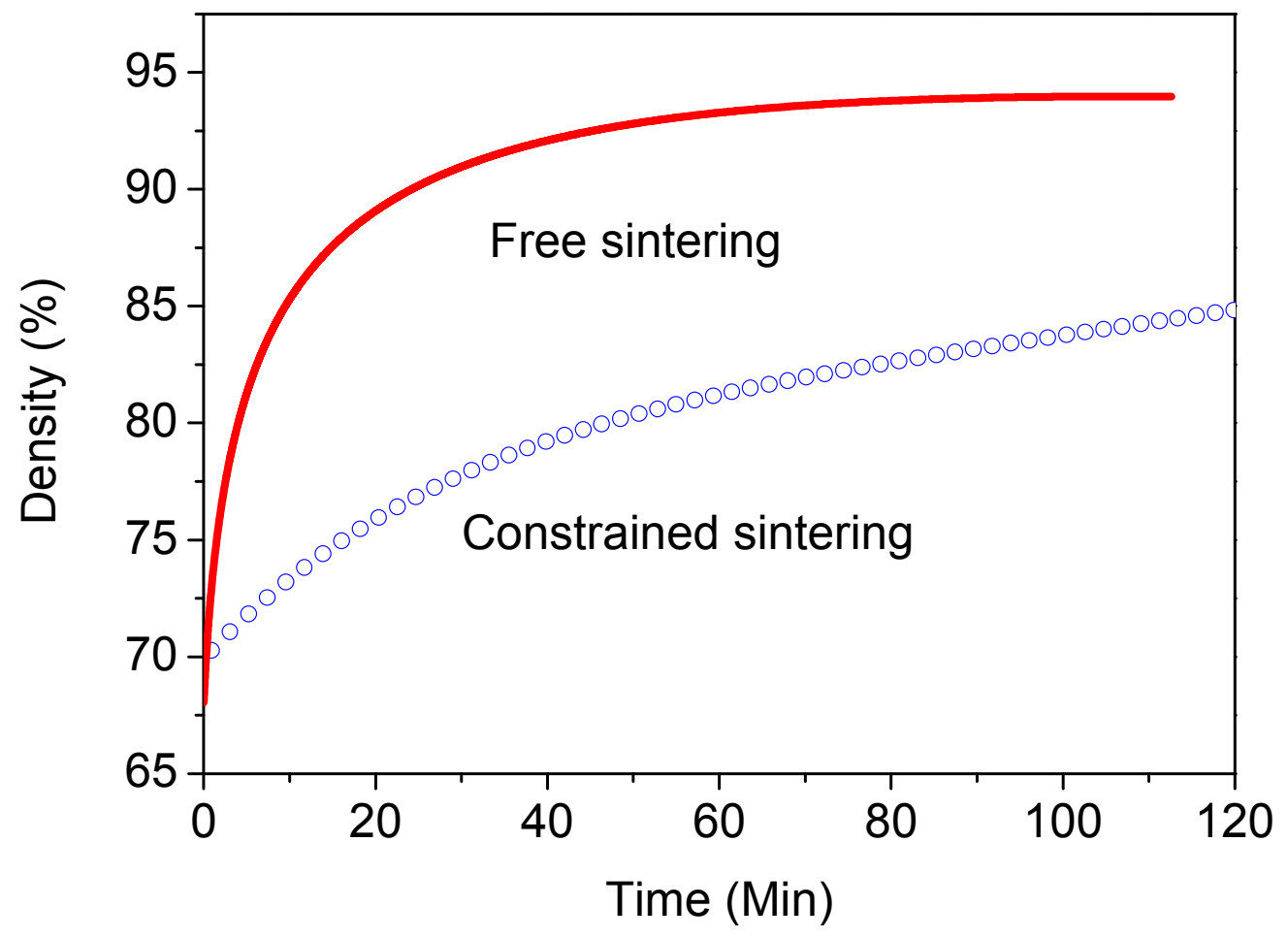

Figure 8 An example (at $1250^{\circ} \mathrm{C}$ ) comparing the isothermal densification kinetics of the constrained and free specimens. 


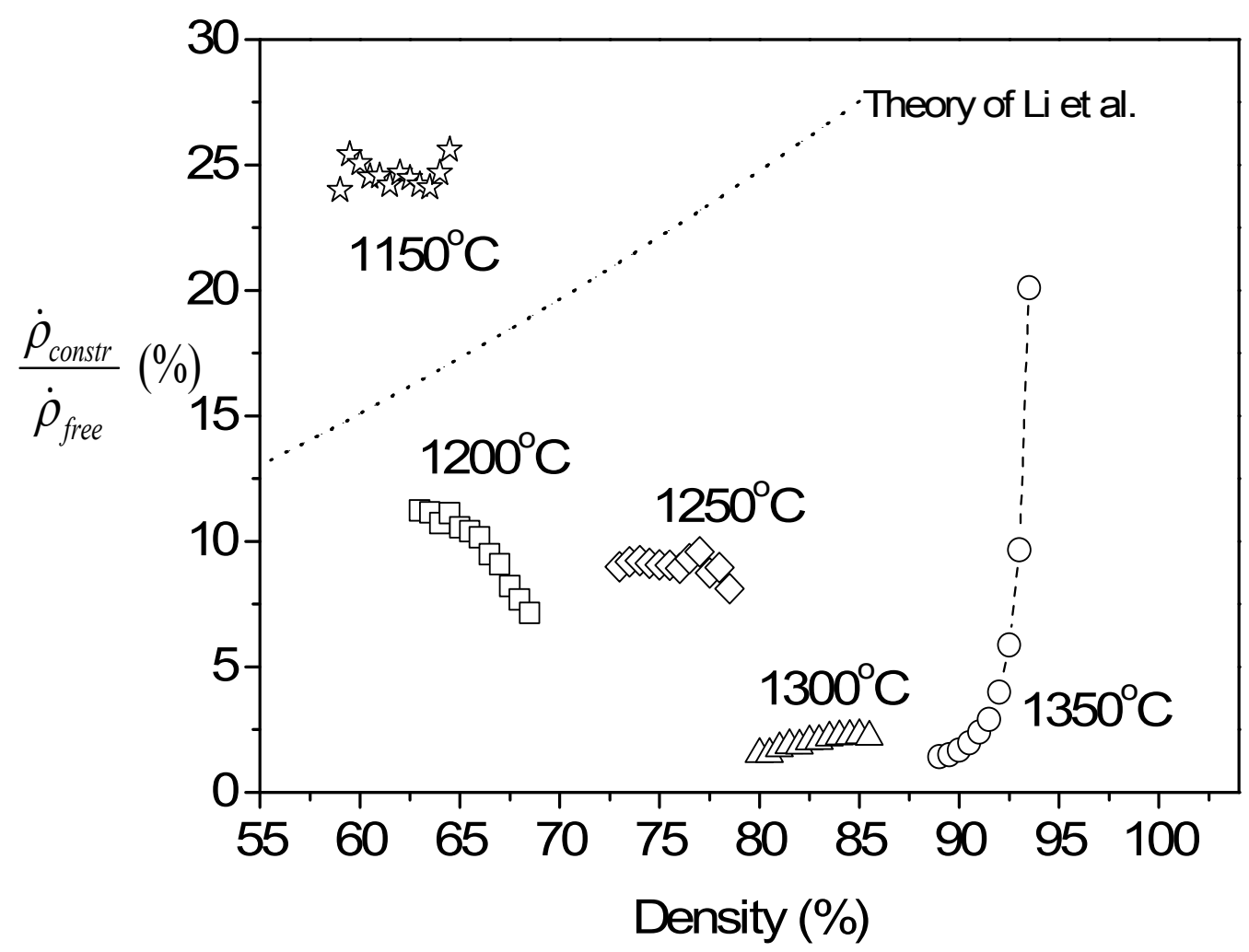

Figure 9 The ratio of constrained to free densification rates as a function of density at different isothermal temperatures. 


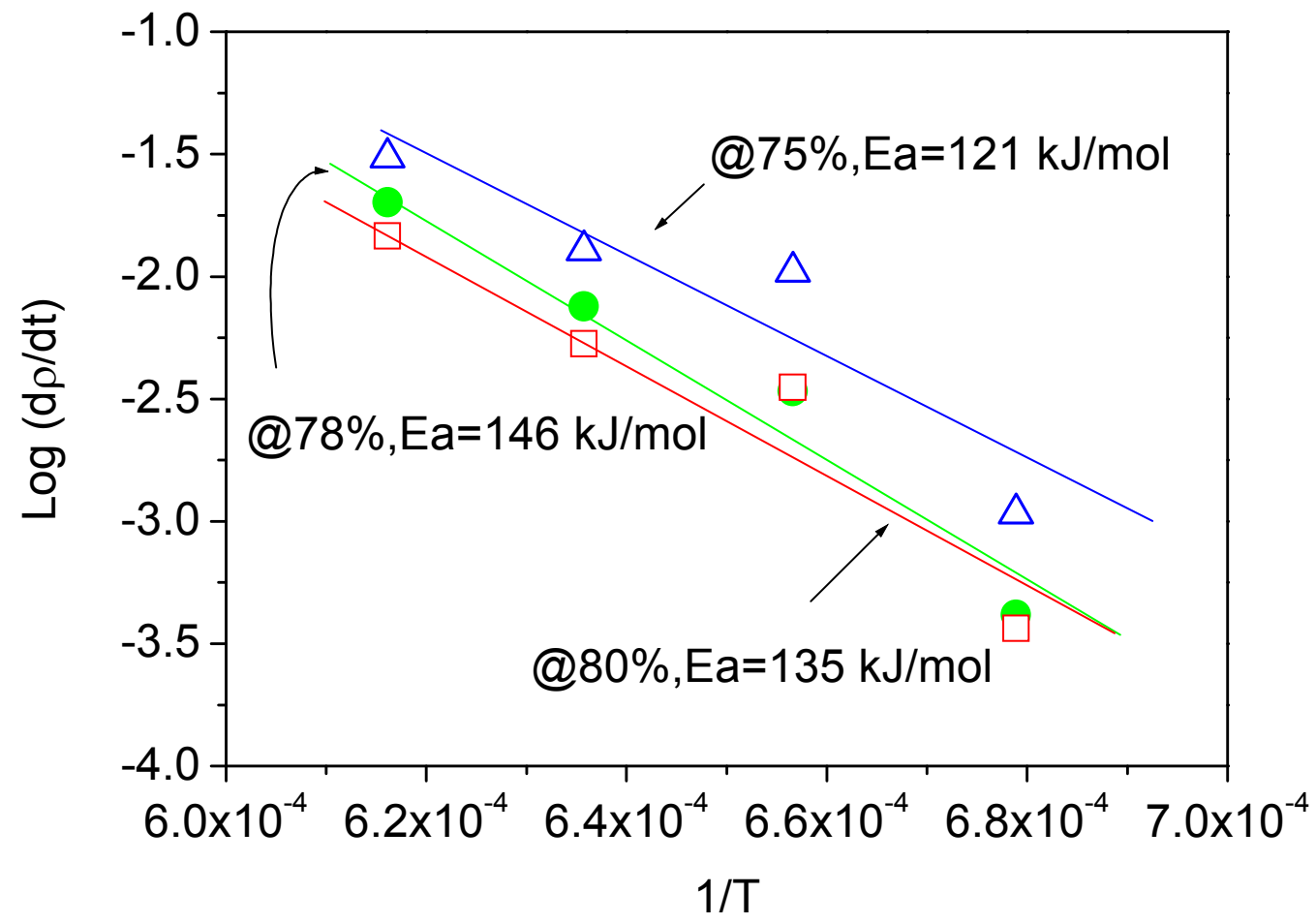

Figure 10 Arrhenius plot of the constrained densification rates at different densities. 


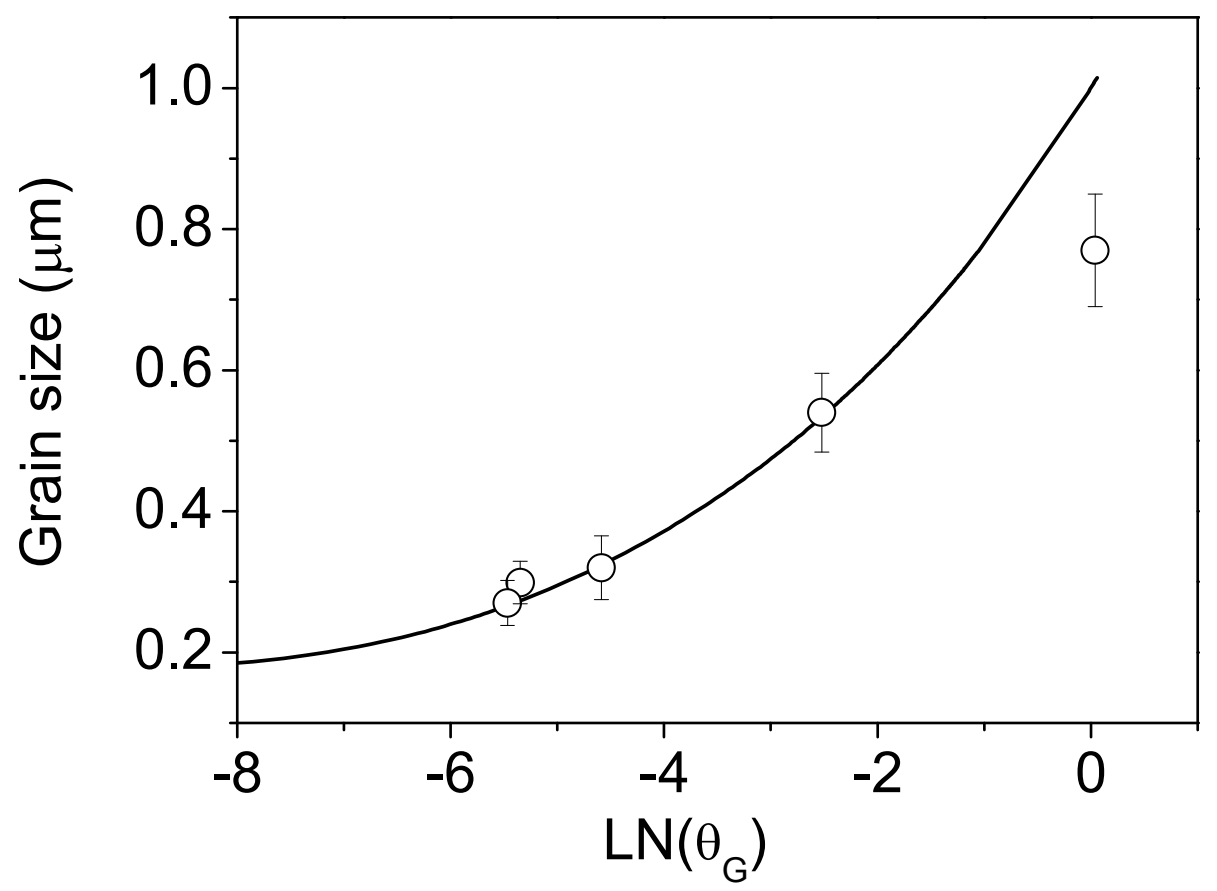

Figure 11 Master curve for grain growth in 3YSZ. 
a)

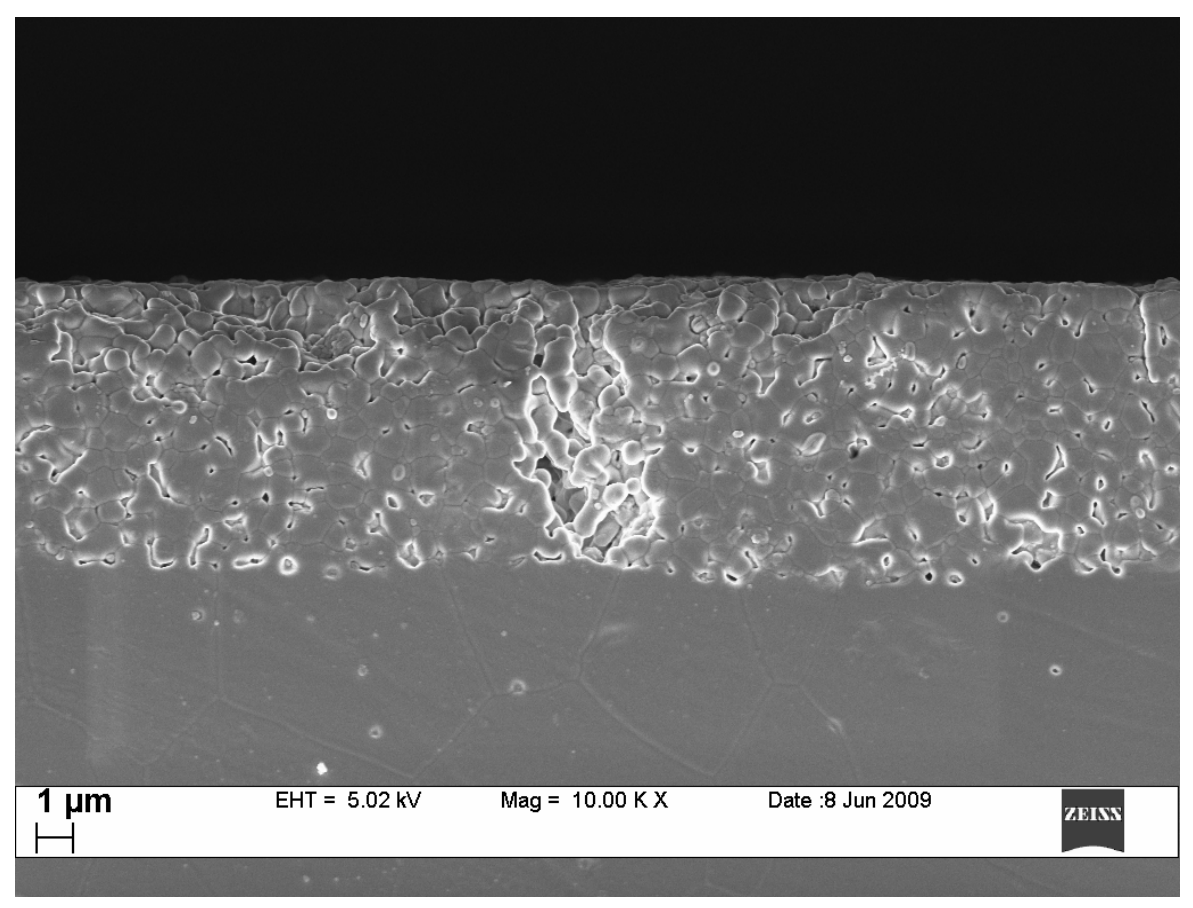

b)

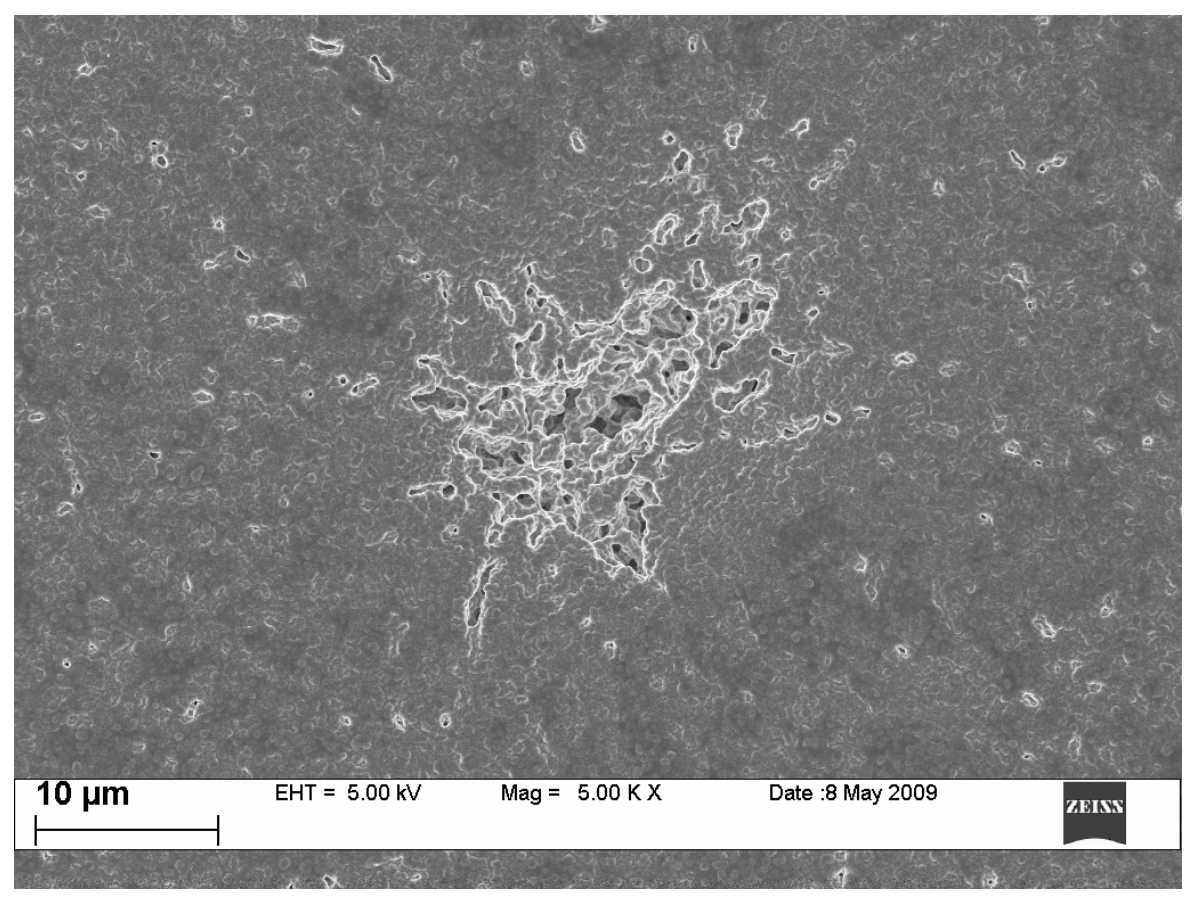

Figure 12 Examples of the microstructure after constrained sintering at $1350^{\circ} \mathrm{C}$ for $1 \mathrm{~h}$ :

a) film cross section; b) top surface. 


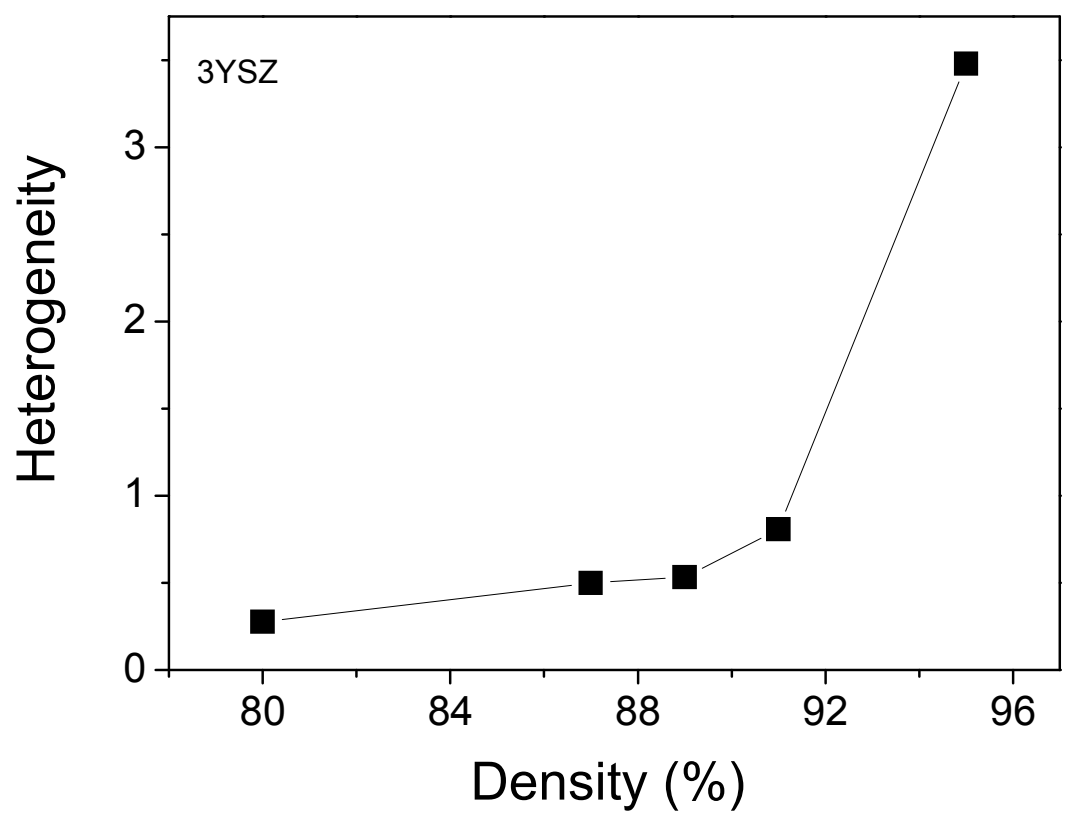

Figure 13 Heterogeneity of the pore distribution (volume ratio of the abnormally large pores over that of normal pores) as a function of density of the constrained film. 